CASE STUDY

\title{
Students as partners in digital education: Exploring lecture capture in higher education through partnership between students and learning technologists
}

\author{
*Karl Luke, School of Medicine, Cardiff University, UK. \\ Geraint Evans, Centre for Education Support and Innovation, Cardiff University, UK. \\ Contact : karl.luke1@southwales.ac.uk
}

\begin{abstract}
This case study reports on two student-staff partnership projects at Cardiff University that explored the student experience of using lecture capture technologies. We describe the background to these projects, how they were designed, and how students and staff worked together to gain insights into the student experience. The case study demonstrates that nuanced understandings regarding the way students use lecture recordings is required and argues that student-staff partnership is an effective way of achieving these understandings. Suggestions are offered regarding how educationists could further harness partnerships to explore the complex interplays between technology and student learning. This reflective account also explores our efforts in achieving meaningful partnership working, the challenges encountered, and highlights the benefits of partnerships between students and professional-services staff, specifically learning technologists.
\end{abstract}

KEYWORDS

student as partners, lecture capture, non-academic partnerships, learning technologists, student partnerships

\section{BACKGROUND}

\section{Student partnership}

Student partnership is an idea that has gained much traction in higher education in recent years. The concept of Students as Partners (SaP) has increasingly been used to describe ways in which institutions approach the important yet challenging task of engaging students with decisions around the design and delivery of their educational experience (MercerMapstone et al., 2017). 
Whilst the SaP concept can encompass a range of practice, we focus specifically on the relationships between staff and students and the opportunities afforded by such partnerships (Baumber et al., 2020). We have framed our discussion around our experiences as SaP project supervisors, specifically focussed on types of student-staff partnership whereby "staff and students work collaboratively with one another to create components of curricula and/or pedagogical approaches" (Bovill et al., 2016, p. 196). This case study considers two interrelated projects at Cardiff University, a member of the research-intensive UK Russell Group of universities, which used student-staff partnerships to explore the student experience of lecture capture.

\section{Lecture capture}

The recording of teaching events, such as lectures (lecture capture), is fast becoming an established practice within higher education, with many global universities adopting lecture capture to support blended learning approaches (Morris et al., 2019). A centralised lecture capture solution was implemented at Cardiff University in a phased rollout in 2015. Initially, lecture recording operated on an opt-in basis before a university policy in 2018/19 mandated that all timetabled lecture activities be automatically recorded unless the principal contributor had opted out in advance. This policy was a direct response to student demand and was part of the university's strategic commitment to support flexible, digital, and independent learning (Cardiff University, 2018).

The practice of lecture capture is a "contested space" amongst staff and students in relation to both the use and value of lecture recordings (Morris et al., 2019). The value of lecture capture has been evaluated and debated from a number of perspectives, including inclusivity and pedagogic impact (both positive and negative) on student learning (Nordmann et al., 2020). However, much lecture capture literature oversimplifies the nuances and complexities surrounding digital learning and teaching (Luke, 2020). Importantly, the active role learners can play in supporting the development, implementation, or evaluation of lecture capture systems and policies appears to be largely underreported in the literature (Evans \& Luke, 2020).

\section{Student partnership projects}

Cardiff University Student Education Innovation Projects (CUSEIP) "enable students to work on learning and teaching enhancement projects that will help shape the student experience" (Cardiff University, 2018). These projects support student-staff partnership by providing a bursary to underwrite summer placement opportunities for students within schools and other departments. Students are supervised by a member of staff and carry out a project relating to one of a number of specified themes, all based around enhancing teaching, learning, or assessment. This case study explores two such projects (Table 1) initiated to explore students' experiences and perspectives of lecture capture during the initial opt-in phase at Cardiff University. 
Table 1: Overview of CUSEIP projects

\begin{tabular}{|l|l|}
\hline PROJECT NAME & DESCRIPTION \\
\hline $\begin{array}{l}\text { CUSEIP Uni } \\
\text { (2017) }\end{array}$ & $\begin{array}{l}\text { This project was coordinated by the central university support team for } \\
\text { lecture capture in partnership with a year two student from the School } \\
\text { of Chemistry. The scope was university wide and the project researched } \\
\text { and disseminated the different ways students utilised lecture recordings } \\
\text { as part of their private study. Outputs included a series of student-facing } \\
\text { materials, such as an online tutorial and instructional videos. }\end{array}$ \\
\hline $\begin{array}{l}\text { CUSEIP School } \\
\text { (2018) }\end{array}$ & $\begin{array}{l}\text { This project evaluated the student experience of lecture capture in the } \\
\text { School of Social Sciences. The project was an opportunity to surface the } \\
\text { student voice and ensure student perspectives were considered in } \\
\text { individual and school decision-making. The project also delved deeper } \\
\text { into some of the findings surfaced by the previous CUSEIP project. }\end{array}$ \\
\hline
\end{tabular}

\section{METHODS}

Both CUSEIP projects explored students' use of lecture recordings. When supervising these projects, we both held roles as learning technologists within Cardiff University (Mitchell et al., 2017) and we assumed a supervisor role on the projects. This reflective case study is framed around our experiences and perspectives as supervisors and was written several months after the completion of the projects. In the development of this account, contemporaneous emails, documents, project notes, and outputs were revisited, and we critically discussed and reflected upon our experiences. Our reflections were subsequently triangulated with relevant SaP literature. Within this account, supervisor and student quotes are offered to illustrate points. These were collected during the projects and used at the time for internal reports and presentations disseminating project outputs. An unfortunate limitation of this account is the lack of direct student involvement in the publication process, primarily as the students who undertook the projects have since graduated and left the institution. Nonetheless, we believe our account and reflections are of scholarly value, particularly our experiences as professional services staff in engaging with partnership initiatives, which appears to be underreported in the SaP literature.

\section{PROJECT ROLES AND RESPONSIBILITIES}

Both CUSEIP projects were framed by a desire to undertake original research, employing a range of methods including surveys, interviews, and quantitative data analysis. The research design has been previously reported by Evans and Luke (2020). Both placement students acted as co-researchers and pedagogical co-designers during the placements (Bovill et al., 2016) with responsibility for shaping the research methodology and instrument designs (i.e., survey questions), undertaking research and analysing data, and co-designing learning and teaching resources. The partnerships permitted access to specific student insights and perspectives, which actively shaped the development of questions not previously considered by faculty staff (Evans \& Luke, 2020). It was also hoped that participants would be candid when talking to a fellow student, which was perceived as a strength of this approach. The students also led on 
the development and cascading of resources such as online videos, tutorials, and strategic reports.

\section{OUTPUTS AND IMPACT}

A number of recent studies (French \& Kennedy, 2017; Mackay, 2019; Nordmann et al., 2020) argue for improved practical guidance for students and staff on how lecture recordings can be integrated effectively into educational practices. Attempting to address this issue, the student involved in the CUSEIP Uni project co-designed and authored several online resources, including posters, video tutorials, and an interactive online tutorial, to support students' constructive use of lecture recordings. These resources have been satisfactorily evaluated by students with feedback suggesting that learners rate their authenticity, relatability, and coherence. We would argue that student partnership is an efficient and effective way of creating such resources.

Similarly, the CUSEIP School outputs informed the development of two student-facing resources around lecture capture. The resources focused on gaps in student knowledge identified within the project and included instructions on using the functionality of the tool, strategies for integrating lecture capture within learning, and an explanation of the local recording policy. This latter area was important as the project findings exposed student frustrations around the inconsistent approach to lecture capture provision within the school. The resource was purposefully designed to communicate the reasons behind the varied approaches and to manage student expectations around the use of lecture capture.

Perhaps the greatest impact of these projects was the way that the research findings contributed to conversations and decision-making around lecture capture at various levels within the university. For example, a key output from the CUSEIP School project was an extensive report on students' perceptions of lecture capture, which reported on data obtained via student surveys, interviews, and system usage. This data suggested that students highly value lecture capture provision and largely use recordings to overcome barriers and supplement live lectures rather than as a direct replacement. Such findings were reported at various forums within the school, and the outputs improved understandings of students' use of lecture capture and helped shift negative perceptions by focusing on aspects previously unconsidered within the school. Whilst such findings are consistent with recent studies (Morris et al., 2019; MacKay, 2020; Nordmann et al., 2020) they were nonetheless important; it was critical to show that these general trends applied to our students. As such, we believe these projects helped move the institutional conversation around lecture capture from "should we use it?" to "how should we use it?"

\section{BENEFITS}

The experiences of these projects have confirmed that there are a host of benefits to be gained from exploring partnership with students. These include benefits reported by Hill et al. (2019), such as supporting a diversity of perspectives across the university, increased productivity, and synergistic learning opportunities for both staff and students. For example, Figure 1 shows the CUSEIP Uni placement student assisting with the trialling of an innovative whiteboard capture technology and cooperative learning between the student and staff. 


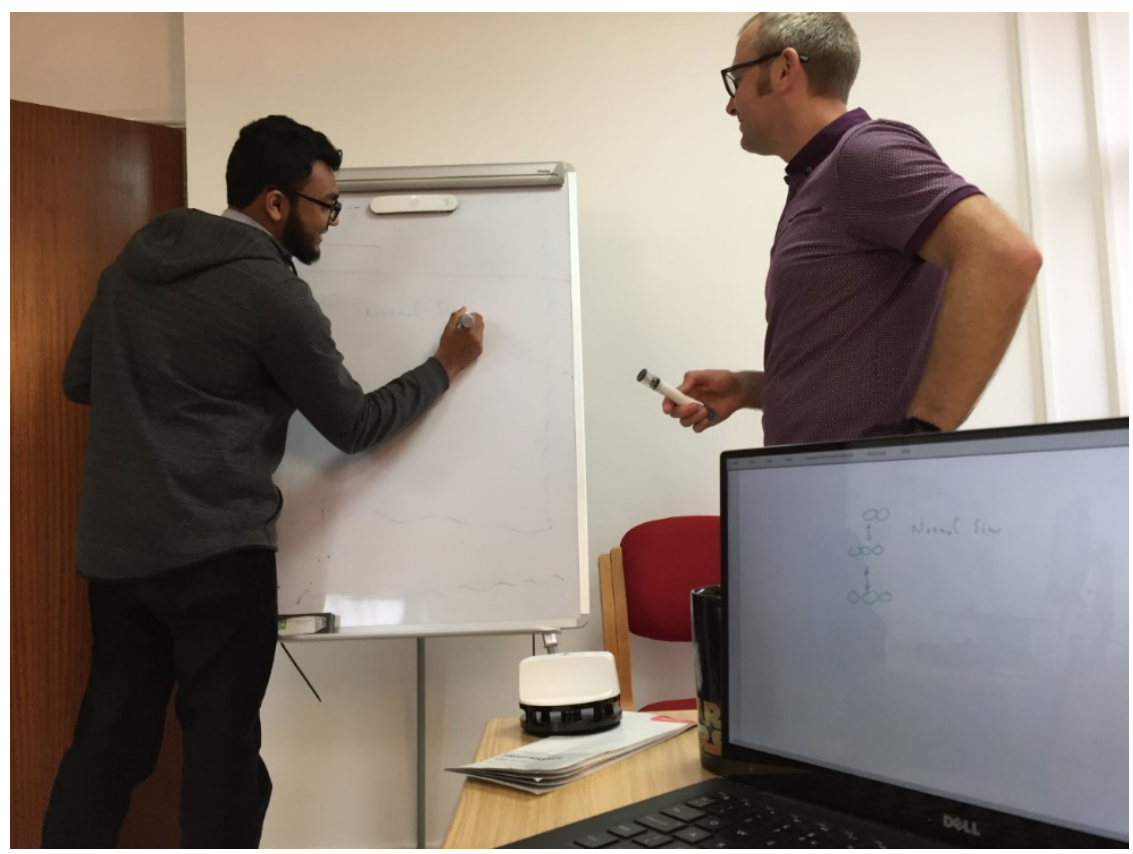

Figure 1. CUSEIP Uni placement student (left) assisting in a trial of whiteboard capture technologies.

Projects such as these can aid our understanding of the complex and messy area of student experience and provide access to diverse perspectives and marginalised voices (Hill et al., 2019). Additionally, the projects developed new and unexpected insights. For example, a significant number of students (around $20 \%$ on both projects) claimed they sometimes watched lecture recordings in collaborative settings alongside fellow students (Evans \& Luke, 2020). As argued by Hill et al. (2019), an advantage of partnership working can be increased productivity. This is something we found on our projects whereby students and staff took responsibility for various elements of the project, supporting effective and efficient working and increasing the capacity to achieve a discrete package of work in relatively short timeframes.

Importantly, the student-staff partnership presented opportunities for staff and students to learn from each other through active participation (Hill et al., 2019). One placement student, Amy, reported in a post-project presentation: "It has been a very valuable experience for me to work alongside staff and see all the work that goes into different aspects of learning for students such as [lecture recording] that I would not have previously thought about." We believe that the placement students have developed a range of key transferable skills and graduate attributes as a result of the placement opportunities, such as enhanced digital literacies, project management skills, and team working experience (Dickerson et al., 2016; Curran, 2017). The placements also enhanced the placement students' understanding of teaching and learning (Jensen \& Bennett, 2016), as evidenced by the following feedback. Ameen, another placement student, commented: "To me this placement was important in assessing my own learning methods and my relationship with technology." Amy explained: 
Before the project I didn't have strong opinions towards [lecture recording]. It has not only allowed me to gain a deeper insight to how [lecture capture] is valued by students but it has also given me ideas of how I could use the technology to benefit my studies in future years of university, and the experience has overall been very eye opening to me.

Importantly, not only were students given a platform to support teaching and learning initiatives, but so too were professional services staff, who are sometimes overlooked in these kinds of enhancement projects. As learning technologists, we found the partnership projects an authentic conduit through which we could open up difficult conversations with academics about teaching practices, directly address colleagues' concerns and fears around lecture capture, and drive positive educational change.

As learning technologists, working alongside students provided genuine benefits above and beyond the scope of the project. The projects increased our understanding of student needs and allowed us to reflect on the importance of regular contact with students, which can be more difficult in such roles compared to our academic colleagues. As one of us noted in our contemporaneous reflections for a "lessons learned" report:

I feel I now have a much clearer insight into how students use lecture recordings and have become a stronger advocate of lecture capture as a result. Carrying out this project has also reinforced the importance of "student voice," something which has at times felt a slightly vague concept.

\section{CHALLENGES}

Depending on the exact shape, scale, and context of student partnership, there are a number of challenges contained within, foremost of which is often time, both in terms of finding space in the schedule for such activities to take place but also allowing time to develop the shared understanding and trust necessary for effective partnership (Bovill et al., 2016; Marquis et al., 2017).

The limited timescales of the projects were always a challenge, despite the duration of the projects being a seemingly generous 12 weeks in the summer period between academic terms, when staff workload was reduced. This was alleviated somewhat by the co-location of staff and students throughout the projects. However, in line with the findings of Hill et al. (2019), we found that both faculty and students needed to commit significant time to engage in meaningful partnership working.

Indeed, it became clear during these projects that true partnership, in the sense of equal ownership between staff and students, can be difficult to achieve and influenced by factors other than time. There are concerns that students may not have the necessary understanding or experience to contribute equally alongside faculty members (Cook-Sather, 2014). This was a feature of these projects, as both students took time to grasp the range of considerations and issues around lecture capture, and much of the direction and coordination of the projects, at least initially, were provided by staff.

There were concerns that the students may not produce genuine insights and were not offered enough agency to engender true partnership, which are concerns that are commonly 
recognised in the SaP literature (Cook-Sather, 2014; Marquis et al., 2017). Additionally, neither student on our projects had previously undertaken paid employment and did not initially demonstrate proficiency in the key $21^{\text {st }}$ century skills and competencies identified by Ananiadou and Claro (2009) for young adult learners: time management, organisation skills, decisionmaking, interpersonal skills, and communication. Improvements were noticed, but it is important to recognise that students, by their very nature, are still very much learners in this context and need to be nurtured and supported.

Thus, establishing a professional rapport, built on trust and respect, are important for effective partnership working (Healey et al., 2014; Hill et al., 2019). This meant understanding the students' personal requirements and needs. For example, the CUSEIP Uni student was required to perform Salat, the obligatory Muslim prayers performed five times each day. Supporting this request, and appreciating that there were times when the student was not in the office, helped build a productive working relationship. Setting agreed goals and establishing mutual expectations was also important, and both projects conducted regular review meetings with the student. The payment of students is a related and important issue; in our projects this helped foster mutual respect, provided a degree of equity in the partnership working, and possibly contributed to developing a professional work ethic in the students. Hill et al. (2019) have also highlighted the importance of the student-to-staff ratio as an important partnership consideration. Both placement students were attached primarily to a small team featuring two staff members, and this direct contact gave both staff and students clear focus, structure, and boundaries to operate within.

We also found that optimal scheduling for objectives to be realised, and for partnership working to be embedded, is a challenge. For example, some of the data collection for the CUSEIP School project relied on student surveys being released before the end of term, which was also before the start of the student placement. The placement also finished before some of the outputs (e.g., student facing resources) could be produced. This removed opportunities for co-design in these elements of the project and further compromised the equal partnership aim of the project.

\section{CONCLUSION}

Partnership is usually dependent on staff creating the opportunities for collaboration (Bovill et al., 2016). These projects offer a good example of where these opportunities can be provided not by academic staff, as is often reported, but by professional services staff, in this case learning technologists. Effective partnerships require a renegotiation of roles (Marquis et al., 2017; Baumber et al., 2020), and our projects can be viewed as "productively disruptive" (Cook-Sather, 2014, p. 190); they provide evidence of the value professional services staff can provide in leading student-focused initiatives and academic endeavors. We would therefore strongly encourage professional services staff to play their part in future student-staff partnership initiatives.

These projects have suggested that there are a host of benefits to be gained from exploring lecture capture through partnership with students. The project outcomes have been well evaluated, and having a student-led perspective afforded opportunities to gain authentic understandings of student learning within the institution. This allowed faculty to discuss and 
explore student expectations and assumptions, and to identify areas for improvement. It gave students authentic opportunities to directly inform and shape a large institutional project in lecture capture.

Currently, the role of student partnerships in supporting the development, implementation, or evaluation of lecture capture systems appears to be lacking in the literature (Evans \& Luke, 2020). It seems likely, given the experiences of our projects, that partnership is an effective route to gain more nuanced insight into study habits relating to the use of lecture capture and, more broadly, use of learning technology. We have exposed underreported areas within the current lecture capture literature, such as students' use of lecture recordings in collaborative settings and their use of active learning strategies, as reported by Evans and Luke (2020).

However, many questions still remain about lecture capture and its effect on learning and engagement, such as the effects of collaborative viewing of lecture material on attainment (Nordmann et al., 2020). Thus, we see opportunities to replicate partnership working to investigate a number of unresolved issues. There are inevitably gaps in our understanding in areas where our projects had small representative samples. For example, how helpful is lecture capture for postgraduate students who have English as a second language, mature students, or students from Black, Asian and minority ethnic (BAME) backgrounds? Student partnership may afford educationalists a unique opportunity to engage in conversations that could bridge these knowledge gaps.

These projects represent partnership in a broad sense, engaging students at the faculty and university level to understand their experiences of and views on the delivery of teaching and learning. Moreover, such projects can help embed partnership working as part of broader institutional goals. Initiatives such as Cardiff University's CUSEIP are crucial for seeding collaborative opportunities and acting as a vehicle for change, though more work is needed to embed and reinforce this kind of practice within the organisational culture of higher education institutions.

\section{ACKNOWLEDGEMENTS}

The authors would like to express their gratitude to the two undergraduate students who undertook the CUSEIP projects-Ameen and Amy-for their hard work and dedication during the placements.

\section{NOTE ON CONTRIBUTORS}

Karl Luke is Head of Digitally Enabled Education at the University of South Wales. Karl is a senior fellow of the Higher Education Academy (SFHEA) and certified member of the Association of Learning Technology (CMALT). Karl's research interests include digital education, multimodality, and sociomateriality. Karl was a learning technologist at Cardiff University and staff supervisor on the projects described in this article. 
Geraint Evans is a Digital Learning Manager at Cardiff University, and a certified member of the Association of Learning Technology (CMALT). Geraint's research interests include digital education and staff-student partnerships. Geraint was a staff supervisor on one of the projects reported in this article.

\section{REFERENCES}

Ananiadou, K., \& Claro, M. (2009). 21st century skills and competences for new millennium learners in OECD countries. OECD Education Working Papers, 41. https://doi.org/10.1787/19939019

Baumber, A., Kligyte, G., van der Bijl-Brouwer, M., \& Pratt, S. (2020). Learning together: A transdisciplinary approach to student-staff partnerships in higher education. Higher Education Research \& Development, 39(3), 395-410. https://doi.org/10.1080/07294360.2019.1684454

Bovill, C., Cook-Sather, A., Felten, P., Millard, L., \& Moore-Cherry, N. (2016). Addressing potential challenges in co-creating learning and teaching: Overcoming resistance, navigating institutional norms and ensuring inclusivity in student-staff partnerships. Higher Education, 71(2), 195-208. https://doi.org/10.1007/s10734-015-9896-4

Cardiff University. (2018). About CUSEIP. [Unpublished intranet document].

Cook-Sather, A. (2014). Student-faculty partnership in explorations of pedagogical practice: A threshold concept in academic development. International Journal for Academic Development, 19(3), 186-198. https://doi.org/10.1080/1360144X.2013.805694

Curran, R. (2017). Students as partners-good for students, good for staff: A study on the impact of partnership working and how this translates to improved student-staff engagement. International Journal for Students as Partners, 1(2), 1-16.

https://doi.org/10.15173/ijsap.v1i2.3089

Dickerson, C., Jarvis, J., \& Stockwell, L. (2016). Staff-student collaboration: Student learning from working together to enhance educational practice in higher education. Teaching in Higher Education, 21(3), pp. 249-265. https://doi.org/10.1080/13562517.2015.1136279

Evans, G., \& Luke, K. (2020). Lecture capture and peer working: Exploring study practices through staff-student partnerships. Research in Learning Technology, 28. https://doi.org/10.25304/rlt.v28.2314

French, S., \& Kennedy, G. (2017). Reassessing the value of university lectures. Teaching in Higher Education, 22(6), 639-654. https://doi.org/10.1080/13562517.2016.1273213 
Healey, M., Flint, A., \& Harrington, K. (2014). Engagement through partnership: Students as partners in learning and teaching in higher education. Higher Education Academy. https://www.heacademy.ac.uk/engagement-through-partnership-students-partnerslearning-and-teaching-higher-education

Hill, J. T., Thomas, C., \& Brown, B. (2019). Research assistant as partner: Collective leadership to facilitate co-production. International Journal for Students as Partners, 3(2), 129-138. https://doi.org/10.15173/ijsap.v3i2.3674

Jensen, K., \& Bennett, L. (2016). Enhancing teaching and learning through dialogue: A student and staff partnership model. International Journal for Academic Development, 21(1), 41-53. https://doi.org/10.1080/1360144X.2015.1113537

Luke, K. (2020). The pause/play button actor-network: Lecture capture recordings and (re) configuring multi-spatial learning practices. Interactive Learning Environments, 1-17. https://doi.org/10.1080/10494820.2019.1706052

Mackay, J. R. D. (2019). Show and 'tool': How lecture recording transforms staff and student perspectives on lectures in higher education. Computers \& Education, 140, 103593. https://doi.org/10.1016/j.compedu.2019.05.019

MacKay, J. R. D. (2020). First year undergraduates make use of recordings to overcome the barriers to higher education: Evidence from a survey. Research in Learning Technology, 28. https://doi.org/10.25304/rlt.v28.2476

Marquis, E., Black, C., \& Healey, M. (2017). Responding to the challenges of student-staff partnership: The reflections of participants at an international summer institute. Teaching in Higher Education, 22(6), 720-735. https://doi.org/10.1080/13562517.2017.1289510

Mercer-Mapstone, L., Dvorakova, S. L., Matthews, K. E., Abbot, S., Cheng, B., Felten, P., Knorr, K., Marquis, E., Shammas, R., \& Swaim, K. (2017). A systematic literature review of students as partners in higher education. International Journal for Students as Partners, 1(1). https://doi.org/10.15173/ijsap.v1i1.3119

Mitchell, K., Simpson, C., \& Adachi, C. (2017, December 4-6). What's in a name: The ambiguity and complexity of technology enhanced learning roles. [Paper presentation]. 34th International Conference on Innovation, Practice and Research in the Use of Educational Technologies in Tertiary Education, Queensland, Toowoomba. http://2017conference.ascilite.org/wp-content/uploads/2017/11/ASCILITE-2017Proceeding.pdf 
Morris, N. P., Swinnerton, B., \& Coop, T. (2019). Lecture recordings to support learning: A contested space between students and teachers. Computers \& Education, 140, 103604. https://doi.org/10.1016/j.compedu.2019.103604

Nordmann, E., Küepper-Tetzel, C. E., Robson, L., Phillipson, S., Lipan, G. I., \& Mcgeorge, P. (2020). Lecture capture: Practical recommendations for students and instructors. Scholarship of Teaching and Learning in Psychology. [Advance online publication]. https://psycnet.apa.org/doi/10.1037/stl0000190 